\title{
$|1||||| \mid$
}

\section{ИССЛЕДОВАНИЯ НАДЕЖНОСТИ ДИОДНЫХ ЛАЗЕРОВ С НЕСКОЛЬКИМИ ОДИНОЧНЫМИ ИЗЛУЧАТЕЛЯМИ ВЫСОКОГО УРОВНЯ ЯРКОСТИ}

Цзин Чжу, Томас Ян, Цуйпэн Чжан, Сяочэнь Цзян, Жуй Лю, Яньянь Гао, Вэйжун Го, Юйхуа Цзян, Ян Лю, Луянь Чжан, Луиза Чэнь, BWT Beijing Ltd., Пекин, KHP

Операции монтажа лазерных кристаллов в лазерные линейки и решетки - сложные и дорогостоящие процессы, которые определяют выходные параметры готовых приборов. Для получения лазерных диодных модулей с высокими оптическими характеристиками и высокой надежностью возникает необходимость в проведении ускоренных испытаний на долговечность. Представлены результаты испытаний лазерных модулей из различных кристаллов. Показано, что при оптимальном монтаже удается создавать модули со стабилизированной длиной волны. Достигнуть значения показателя наработки на отказ 177710 часов с доверительным интервалом 60\%.

\section{1. ВВЕДЕНИЕ}

Благодаря хорошему качеству луча и гибкости использования в работе, мощные диодные лазеры с оптоволоконной связью нашли широкое применение в промышленности, в военной и медименение в промышленности, в военной и меди
цинской областях, технологии печати и в сфере цинской областях, технологии печати и в сфере
обработки материалов [1]. Ввиду растущего обработки материалов [1]. Ввиду растущего в последние годы объема исследований эффе тивность работы мощных диодных лазеров резко повысилась. В настоящее время лазеры в виде линейки или решетки диодов могут вырабатывать излучение до сотни ватт выходной мощности. В некоторых отдельных прикладных приложениях существует необходимость использоват лазеры, непрерывно работающие на протяжении нескольких лет или даже десятилетий. То есть существует потребность в использовании диодных лазеров с высокой выходной мощностью, но при этом возникает необходимость поддерживать охлаждение таких диодных лазеров для обевать охлаждение таких диодных лазеров

Исследования способов крепления кристаллов на подложке стали необходимы при создании приборов с высокими характеристиками. Для поиска оптимального крепления были исследованы различные кристаллы, полученные от разных мировых поставщиков. С помощью подбора оптимальной схемы охлаждения, усовершенствовани конструкции и технологии корпуса оптической системы была достигнута более высокая надежность работы лазерных модулей с несколькими одиночными излучателями. Степень надежности была подтверждена результатами ускоренных испытаний на долговечность, Это позволяет соз- дать диодные лазерные модули с длительным сроком службы, не требующие частого технического обслуживания и обладаюцие высокой степеньо обслуживания

\section{2. ТЕОРЕТИЧЕСКАЯ МОДЕЛЬ}

Предполагая, что механизм отказа является одинаковым для всех видов кристаллов, можно провести ускоренные испытания на долговечность с помощью ускорения наработки на отка изделий, воздействуя на них повышенным рабочими нагрузками или увеличивая параметры воздействия внешней среды. На основании определенных выводов из результатов испытаний на долговечность можно получить коэффициент надежности и параметры, касающиеся срока службы.

Высокая температура является одним из наиболее распространенных видов нагрузок, которые используются в испытаниях на долговечность. В соответствии со стандартом Telcordia GR468CORE [2] модель Аррениуса описывает влияние температуры на срок службы изделий. Связь между ними показана в уравнении:

$$
\mathrm{L}=\operatorname{\beta exp}\left(\frac{\mathrm{E}_{\mathrm{a}}}{\mathrm{kT}}\right),
$$

где L - параметр, отображающий срок службы, например, средний срок службы, медианный срок службы и т.п.; $\beta$ - положительная константа, которая относится $\mathrm{K}$ характеристикам и геоме трическим формам изделия; Е - энергия активации, измеряемая в электроновольтах; $\mathrm{k}$ - постоянная Больцмана $\left(8,617 \cdot 10^{-5}\right.$ эВ/K); Т - абсолютная температура в градусах Кельвина; модель Аррениуса показывает, что параметр, описывающий срок службы, экспоненциально снижается при повышении температуры.

На основании уравнения связи Аррениуса можно определить коэффициент ускорения между сроком службы при температуре $\mathrm{T}_{2}$ и сроком службы при температуре $\mathrm{T}_{1}$ :

$$
\tau_{\mathrm{T}}=\frac{\mathrm{L}_{2}}{\mathrm{~L}_{1}}=\exp \left(\frac{\mathrm{E}}{\mathrm{k}}\left(\frac{1}{\mathrm{~T}_{2}}-\frac{1}{\mathrm{~T}_{1}}\right)\right),
$$

где $\mathrm{T}_{1}$ и $\mathrm{T}_{2}$ - соответственно температура нормальной работы и температура ускоренного испытания на долговечность; $\mathrm{L}_{1}$ и $\mathrm{L}_{2}$ - соответственно срок службы при нормальной работе и срок службы в условиях проведения ускоренного испьтания на долговечность. Значение показателя энергии активации $\mathrm{E}_{\mathrm{a}}$ обычно предоставляется поставщиком кристалда или это значение берется из результар ускоренных испытаний на долго-

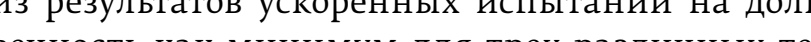
ператур. Ксходя из опьча, похазатель $\mathrm{E}_{\mathrm{a}}$ находится в пределах диапазона $0,41-0,64$ эВ; в данном

При $\mathrm{T}_{2}>\mathrm{T}_{1}$ температурная нагрузка влияе на надежность работы. Для комнатной температуры 298К и температуры ускоренных испытаний на долговечность $308 \mathrm{~K}$ уравнение (2) дает коэффициент ускорения $\tau_{\mathrm{T}}=1,8$. Другими словами, при каждом повышении температуры на 10K период испытания сокращается почти вполовину.

Электрические нагрузки, такие как ток возбуждения и электрическая мощность, могут также применяться в ускоренном испытании на долговечность. Коэффициент ускорения $\tau_{\mathrm{T}}$ между сроком службы при мощности $\mathrm{P}_{2}$ и сроком службы при мощности $\mathrm{P}_{1}$ следующий:

$$
\tau_{\mathrm{p}}=\left(\frac{\mathrm{P}_{2}}{\mathrm{P}_{1}}\right)^{\mathrm{n}}
$$

где $\mathrm{P}_{1}$ и $\mathrm{P}_{2}$ - соответственно номинальная мощность диодного лазера и чрезмерно использованная мощность в ускоренном испытании; n - положительная константа, которая относится к энергии активации. Согласно данным, предоставленным поставщиком кристалла [3], $\mathrm{n}=5,0$.

При повышении мощности на 10\% коэффициент ускорения составляет $\tau_{\mathrm{T}}=1,6$, а время испьтания сокращается примерно на 40\%. С помощь испытания, в котором используется повышенная температура и повышенный показатель тока возбуждения, можно выполнить оценку параметра долгосрочной надежности диодного лазера
в ограниченном промежутке времени, повышая его продуктивность существенным образом.

3. МЕРЫ ПО ПОВЫШЕНИЮ НАДЕЖНОСТИ РАБОТЫ

Среди многих важных факторов, влияющих на показатель долгосрочной надежности диодного лазерного модуля, в настоящем исследовании основное внимание было обращено на два фактора: надежность крепления кристаллов и надежность работы лазерных модулей.

3.1. Надежность крепления кристаллов Для того, чтобы повысить выходную мощность и срок службы диодного лазера, важно обеспечить условия для эффективного рассеяния вырабатываемого тепла с целью снижения тепловой нагрузи, испитываемой кристаллом во время рабозия исп

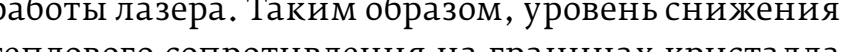
й и на контактном элекриеском сопротивлении является очень критичным параметром. Особенно важно наличие хорошего контакта между кристаллом и подложкой. Наличие слабого контакта или появление пузырьков воздуха между кристаллом и подложкой, образовавшихся в процессе прикрепления кристалла к подложке, приведет к неисправностям в работе лазера. Таким образом, надежность крепления кристалла оказывает решающее влияние на диодный лазер.

В настоящем исследовании рассмотрены преимущества и недостатки мягкого припоя и твердого припоя. Параметры подложки и параметры крепления оптимизируются соответственно в отношении кристаллов с различными длинами волн и разичной выходной моцностьр, которие боли й разлий

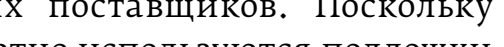

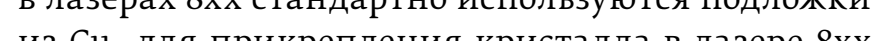
из Cu, для прикран используется мякий припой с использованием индия, то это снижает нагрузку, провоцируемую месоответствием между коэффициентами теплового расширения положки и кристалла. При соответствующем выборе материала для подложки применяется твердый припой с использованием сплава из золота и олова (AuSn) с целью крепления кристаллов в мощных лазерах 9хх, при этом его преимущества представлены высокой прочностью сварки и хорошей усталостной стойкостью. 
Созданы специализированные компоненты для припоя при оптимизации структур подложки и дальнейшей регулировки параметров процесса. Были изучены крептения кристалтов в лазерах С длиной волны от 600 нм до 1550 нм.

Существует четыре основных способа для проСуи сауества ирепления кристаллов на положке. Первый способ - визуальный осмотр. При этом место соединения припоми пров осмоте под микроскопом С лля огределения состояй ст перйо (напий является ли при ей овн являетя ли приной окисленным). Во вторых, для проверки быстроты пайки между кристаллом и подложкой могут использоваться инструмент испытаний на сдвиговые напряжения. В-третьих, можно сканировать кристалл на подложке с помощью ультразвуковой установки. При этом для обнаружения износа или наличия пузырьков воздуха проверяется припой. Наконец, мы можем провести испытание оптических и электрических характеристик КНП. Если КНП не спаян надлежащим образом, повышенный уровен теплового сопротивления приведет и сбою работы устройства во время испытаний на отказ или исследований.

Способ оптимизации процесса крепления индием В испытаниях участвовали 5 образцов КНП с неоптимизированным процессом установки и образцов КНП с оптимизированным процессом

установки. Образцы подвергались воздействию высокой температуры $80^{\circ} \mathrm{C}$. Окисление припоя индием в КНП наблюдалось через одну неделю после хранения образцов под воздействием высокой температуры. Припой на образцах с неоптимизированнам процессом установии затвердел, мизи тем сай пй пой на образцах с опитмизированным процессом установки все еще остался мягким, и признаки сплавления отсутствовали. Можно считать, что степень надежности КНП улучшается благодаря оптимизации крепления.

Способ оптимизация процесса соединения AuSn

В припое AuSn используется четыре разных процесса соединения (обозначенных A-D, рис.1). В отношении диодных лазеров, в которых используется крепление разных типов, были проведень измерения с помощью испытания максимального обратного напряжения и испытания на принудительный отказ в течение 96 часов. Во вр нудительный олказ в течение 96 часов. Во врем испи й ены результаты спытаний.

Рассматривая значения выходной мощности, коэффициента изменения выходной мощности, оровового тока и коэффициента изменения порогового тока, мы обнаружили, что в соедине-

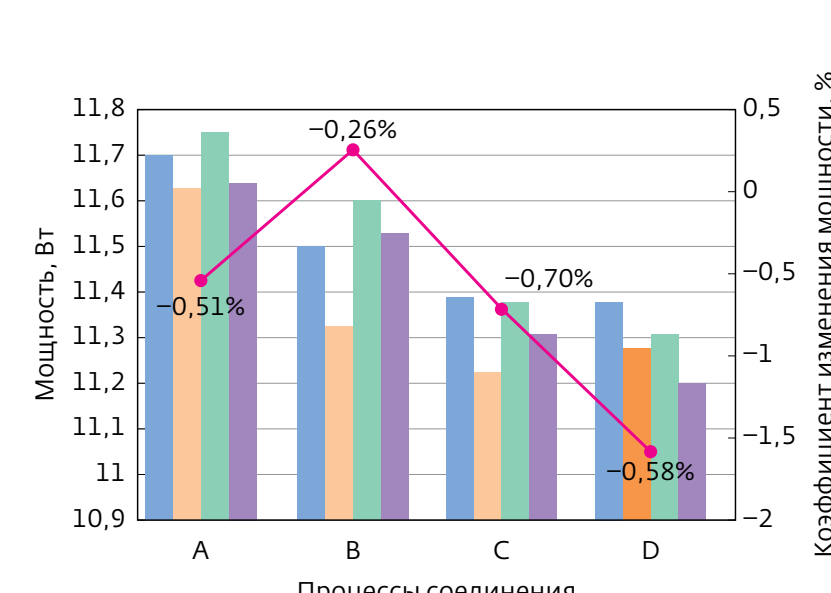$$
\text { Процессы соединения }
$$

- Коэффициент изменения мощностичерез 964

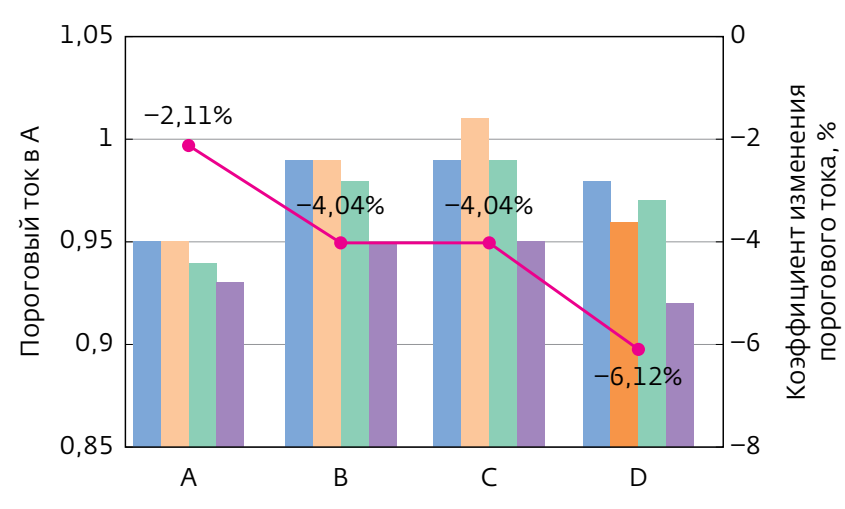

Процессы соединения

$04 \quad 04 \quad 24 \quad \square 484 \square 964$

- Коэффициент изменения порогового тока через 964
Puс.1. Крепление КНП, осуществленное разными типами соединения: $a$ - изменения выходной мощности; $b$ - изменения порогового тока за еремя приработки нии типа А достигнуты следующие параметры: самый высокий показатель выходной мощности КНП, самый низкий показатель порогового тока, минимальный қоэффициент изменения. Путем оптимизации процесса соединения мы можем тобиться увеличения рассеяния тепла Кне добитья увеличения россеяния тепла КНП,

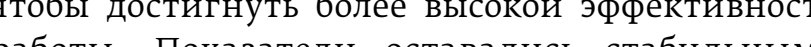
работы. Показатели оставались стабильным и ный отказ.

\section{Способ рассеяние тепла КНП для изделий с высо-} ой тепловой нагрузкой

Сандартные диодные лазеры обладают электрической оптической эффективностью $40-50 \%$; недостатки непрерывно излучающих диодных лазеров на длинах волн 1470 нм или 1550 нм обычно связаны с низкой электрооптической эффективностью и высокой тепловой нагрузкой, их электрооптическая эффективность составляет всего лишь около 20-30\%. Мы считаем, что способ крелления кристаллов в длинноволновом диодном

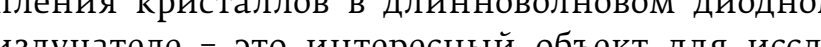
из рова й и может использоваться для целого ряда изделий компании. Модель процесса расприкреплен на подложке) построена с помощью
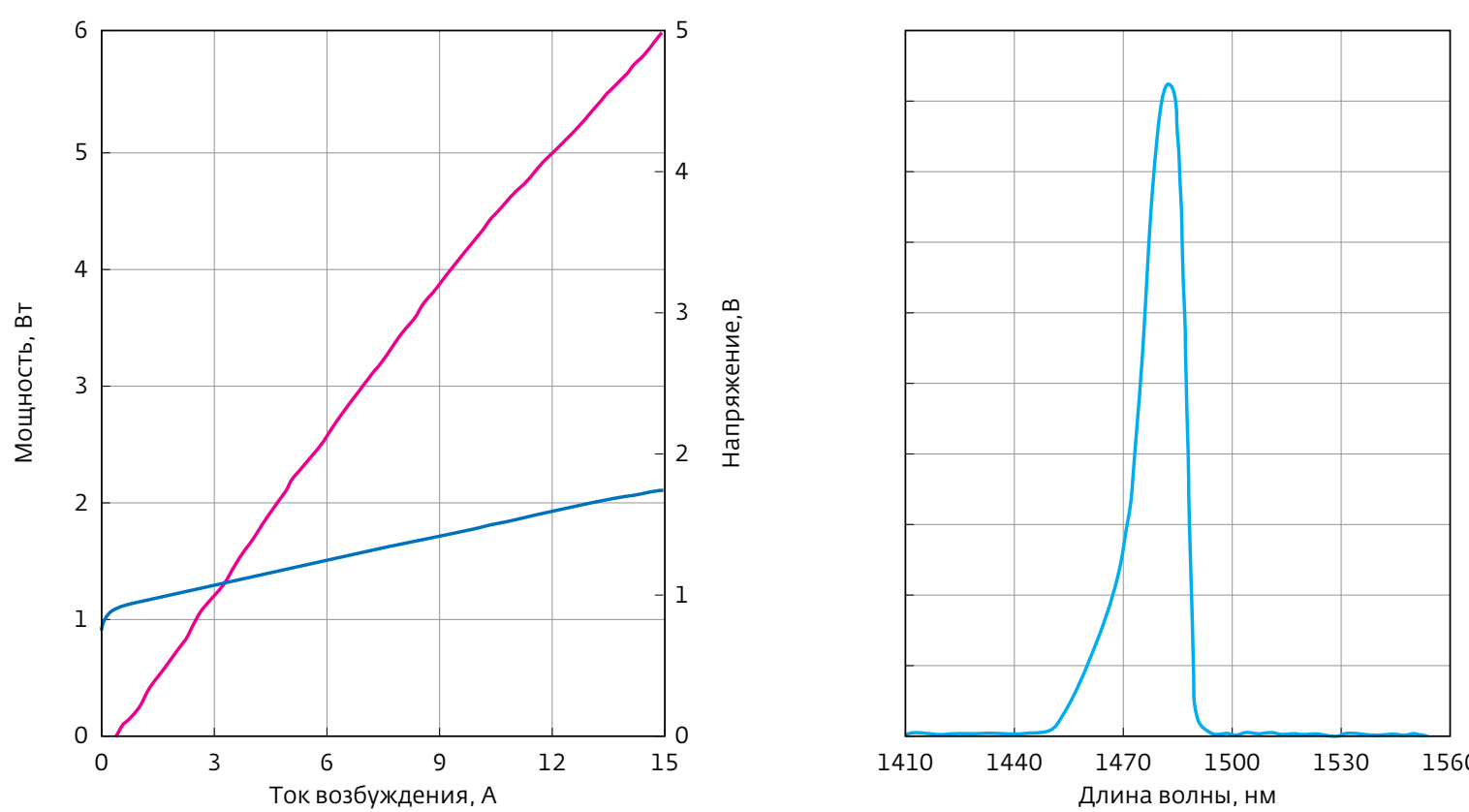

Рис.2. Результаты численного моделирования процесса рассеяния тепла на кристамее, монтаж КНП 
пература контролируется до $25^{\circ} \mathrm{C}$ ), а самая высокая температура на лицевой стороне кристалла составляет $89^{\circ} \mathrm{C}$. Этот оптимизированный про цесс крепления эффективно предотврашает отказ работы кристалла.

Более того, как мы можем увидеть из данных измерений максиматьного обратного напряжения, выходная моцность почти линей но расте с ростом инжекцион ного тока без замееной кривизны или теппового загиба. Это еще раз Котверждает, что этот процесс крепоения раз под эффективным дот процес крепления является с высоким уровнем надежности.

Испытания на долговечность

Кристаллы различных поставщиков, изготовленные из разных пластинок, прошли ускоренные испытания на долговечность для подтверждения долговременной надежности соединения индия и соединения AuSn. Измеренные значения показателя средней наработки на отказ КНП предста зателя средней

КНП 9хх нм, изготовленные из 5 пластин от двух поставщиков, прошли ускоренные испытания на долговечность под воздействием высокой температуры. Согласно теории ускоренного

старения и теории статистики вероятность при уровне доверительного интервала $\mathrm{CL}=60 \%$ и рабочей температуре $25^{\circ} \mathrm{C}$ можно получить показатель средней наработки до отказа. Он составил 203896 часов, то есть около 23 лет. Эти результаты испитаний позть около 23 лет. эти результаты испьтрий поқаты около 23 лет. эти результату исты қристаллами и с высожим качестом. Таким образом, эти КН могу давать высокий уровень выходной мощности, высокую эффективность, длительный срох службы и хорошую долговременную стабильность работы.

\section{2. Надежность работы лазерных}

\section{модулей с несколькими одиночным}

\section{излучателями}

На основе надежных КНП диодные лазеры с несколькими одиночными излучателями могут быть помещены, а затем соединень с волокном 105 мкм для достижения высокого уровня яркости и большой мощности. Поскольку диаметр сердцевины волокна ограничен, даже незначительное смешение и деформашия даже понентов в соединительной дптич могут непосредственни могут непосредственно повлиять на эффекти

Таблица 1. (а) Результаты испытаний долговечности соединения КНП с помощью индия

\begin{tabular}{|c|c|c|c|c|c|c|c|c|c|c|}
\hline $\begin{array}{l}\text { Группа } \\
\text { испыта- } \\
\text { ний на } \\
\text { срок } \\
\text { службы }\end{array}$ & Описание & $\begin{array}{l}\text { Размер } \\
\text { образца }\end{array}$ & Отказ & $\begin{array}{c}\text { Мин. } \\
\text { время } \\
\text { испыта- } \\
\text { ния (4) }\end{array}$ & $\begin{array}{c}\text { Макс. } \\
\text { время } \\
\text { испыта- } \\
\text { ния (4) }\end{array}$ & $\begin{array}{l}\text { Устрой- } \\
\text { ство } \\
\text { испы- } \\
\text { тания } \\
\text { (4) }\end{array}$ & $\begin{array}{l}\text { Устрой- } \\
\text { ство } \\
\text { общего } \\
\text { ускоре- } \\
\text { ния (4) }\end{array}$ & $\begin{array}{c}\text { Токиспы- } \\
\text { тания } \\
\text { долго- } \\
\text { вечности }\end{array}$ & $\begin{array}{c}\text { Темпера- } \\
\text { тура испы- } \\
\text { тания } \\
\text { долговеч- } \\
\text { ности }\end{array}$ & $\begin{array}{c}\text { Наработка } \\
\text { на отказ }\end{array}$ \\
\hline 1 & $\begin{array}{l}830 \mathrm{HM} \\
1,2 \mathrm{BT}\end{array}$ & 32 & 0 & 2064 & 2064 & 66048 & 189610 & 1,4 & 50 & 206931 \\
\hline 2 & $\begin{array}{l}808 \mathrm{HM} \\
10,0 \mathrm{BT}\end{array}$ & 30 & 0 & 1500 & 1500 & 45000 & 135496 & 10,7 & 45 & 147875 \\
\hline
\end{tabular}

\begin{tabular}{|c|c|c|c|c|c|c|c|c|c|c|c|c|}
\hline $\begin{array}{l}\text { Группа } \\
\text { испыта- } \\
\text { ний на } \\
\text { срок } \\
\text { службы }\end{array}$ & $\begin{array}{l}\text { Постав- } \\
\text { щик № }\end{array}$ & $\begin{array}{l}\text { Длина } \\
\text { волны } \\
\text { при 12 Вт }\end{array}$ & $\begin{array}{l}\text { Плас- } \\
\text { тина } \\
\text { № }\end{array}$ & $\begin{array}{l}\text { Размер } \\
\text { образца }\end{array}$ & Отказ & $\begin{array}{c}\text { Мин. } \\
\text { время } \\
\text { испыта- } \\
\text { nия (4) }\end{array}$ & $\begin{array}{c}\text { Макс. } \\
\text { время } \\
\text { испыта- } \\
\text { ния (4) }\end{array}$ & $\begin{array}{l}\text { Устрой- } \\
\text { ство } \\
\text { испыта- } \\
\text { ния (4) }\end{array}$ & $\begin{array}{c}\text { Устрой- } \\
\text { ство } \\
\text { общего } \\
\text { ускоре- } \\
\text { ния (4) }\end{array}$ & $\begin{array}{c}\text { Tок } \\
\text { иппь- } \\
\text { тания } \\
\text { долго- } \\
\text { веч- } \\
\text { ности }\end{array}$ & $\begin{array}{c}\text { Темпе- } \\
\text { ратура } \\
\text { испы- } \\
\text { тания } \\
\text { долго- } \\
\text { веч- } \\
\text { ности }\end{array}$ & $\begin{array}{c}\text { Hара- } \\
\text { боткана } \\
\text { отказ }\end{array}$ \\
\hline 3 & 01 & 915 нм & 1 & 18 & 1 & 818 & 2006 & 35290 & 81706 & 12,5 & 40 & 40402 \\
\hline 4 & 01 & 915 нм & 2 & 18 & 1 & 1652 & 3656 & 64156 & 144539 & 12,5 & 40 & 73450 \\
\hline 5 & 01 & 915 нм & 3 & 18 & 0 & 3656 & 3656 & 65808 & 152364 & 12,5 & 40 & 166283 \\
\hline 6 & 02 & 976 нм & 1 & 24 & 0 & 1992 & 1992 & 47808 & 110689 & 13,0 & 40 & 120801 \\
\hline 7 & 02 & 940 нм & 2 & 24 & 0 & 1992 & 1992 & 47808 & 143878 & 13,0 & 45 & 157022 \\
\hline Bсего & & & & 102 & 2 & & & 260870 & 633176 & & & 203896 \\
\hline
\end{tabular}

потери и снижая выходную мощность. Следовательно, оценка стабильности работы диодных лазеров с несколькими одиночными излучателями является важной частью оценки степени их надежности.

Изменение рабочей температуры приводит К возникнов алте это влияет на выходную мощность лазера. Ста-
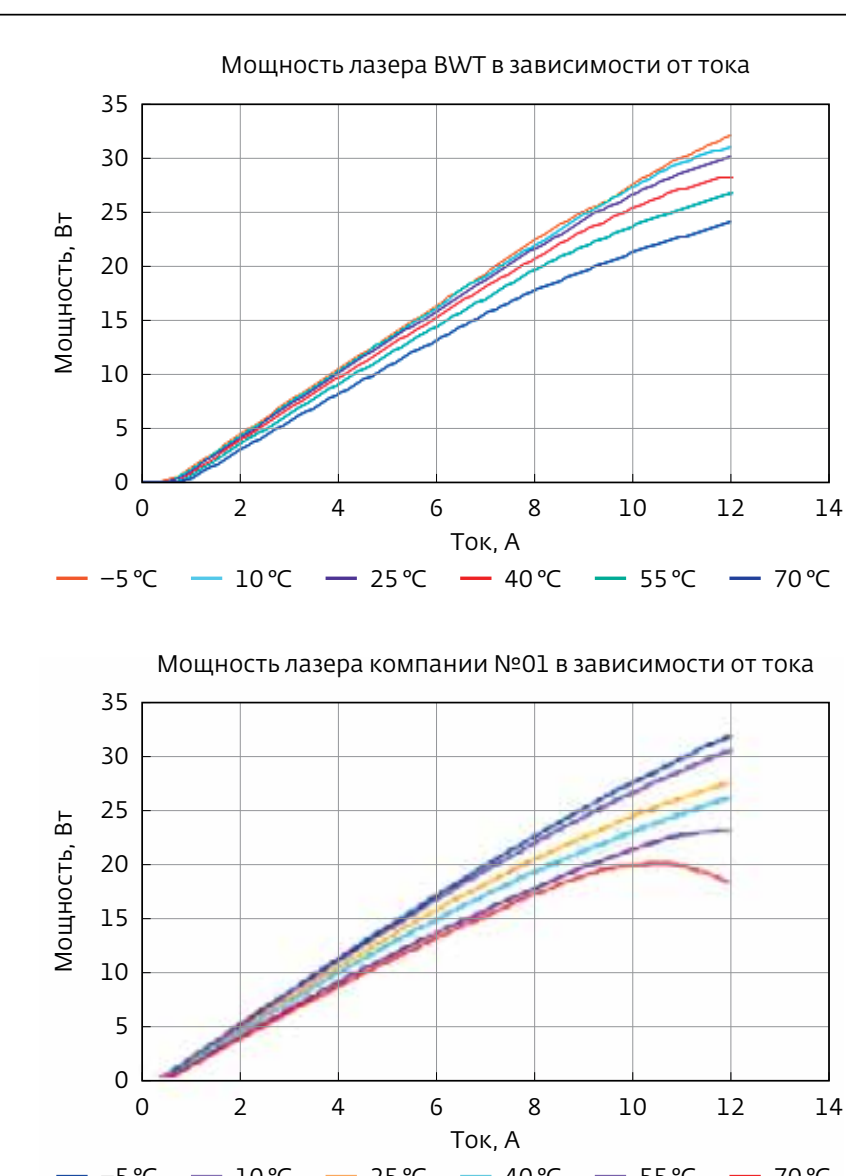

$-5^{\circ} \mathrm{C}-10^{\circ} \mathrm{C}-25^{\circ} \mathrm{C}-40^{\circ} \mathrm{C}-55^{\circ} \mathrm{C}-70^{\circ} \mathrm{C}$

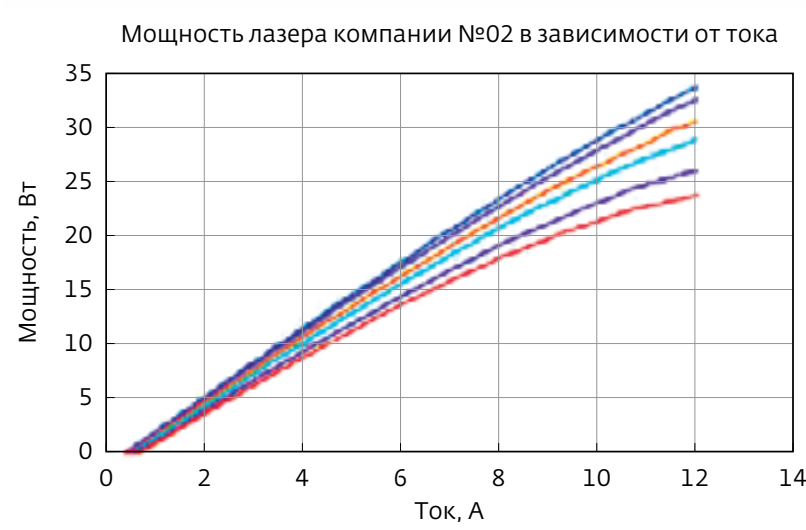

$-5^{\circ} \mathrm{C}-10^{\circ} \mathrm{C}-25^{\circ} \mathrm{C}-40^{\circ} \mathrm{C}-55^{\circ} \mathrm{C}-70^{\circ} \mathrm{C}$

Puс.з. Изменения мощности и спектра изпучения при разиичных рабочих температурах бильность оптических элементов, а также качество соединения могут быть оценены с помощью измерения выходной мощности в зависимости от температуры, изменяющейся в диапазоне от $-5{ }^{\circ} \mathrm{C}$ до $70^{\circ} \mathrm{C}$. Было проведено сравнение по выходной мошности и спектру диодного

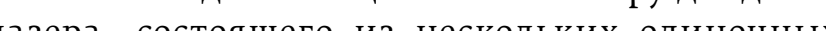
излуча (ей (компания BWT Beijing Ltd.) и двух диодных лазеров с мощностью такого же уровня
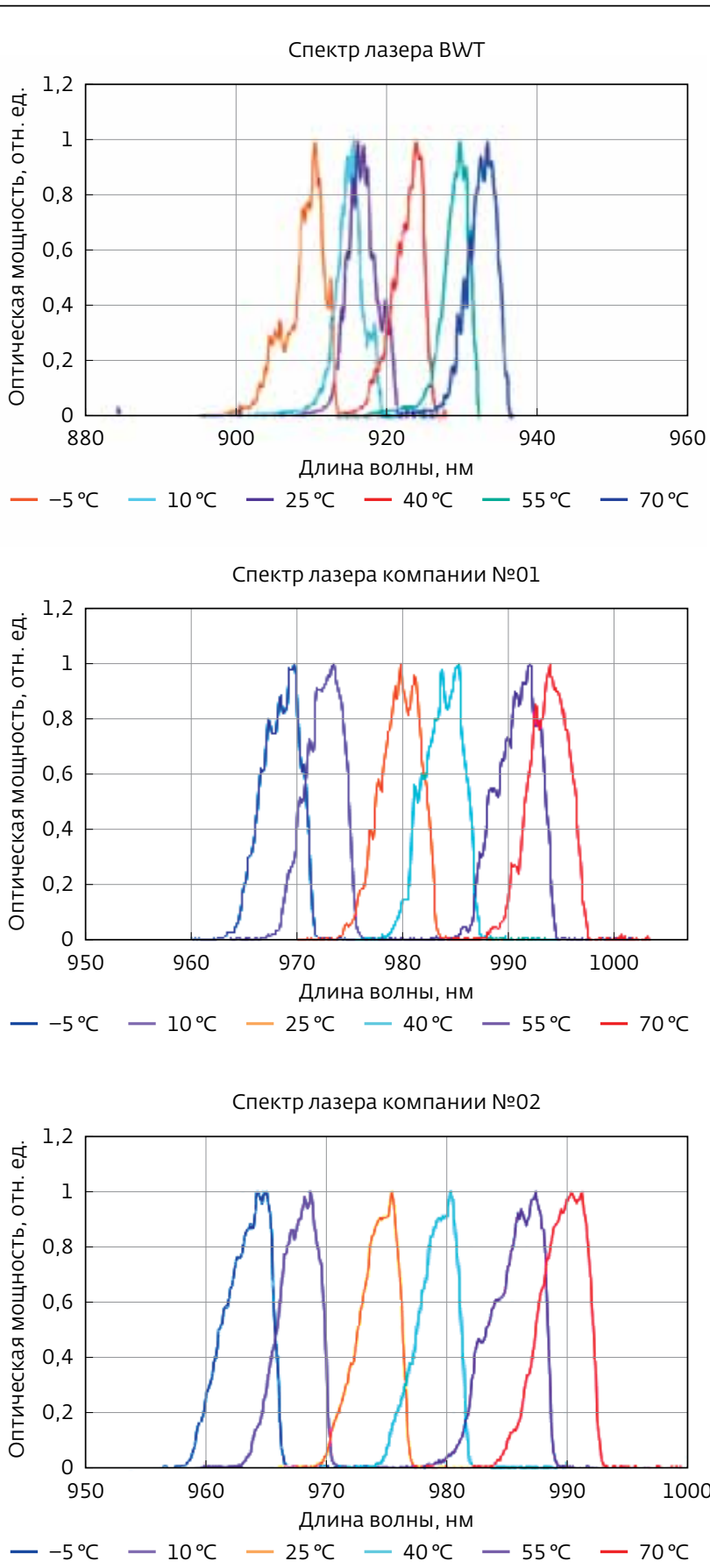

$-5^{\circ} \mathrm{C}-10^{\circ} \mathrm{C}-25^{\circ} \mathrm{C}-40^{\circ} \mathrm{C}-55^{\circ} \mathrm{C}-70^{\circ} \mathrm{C}$ 
и дизайна двух других компаний (компания № 01, компания № 02). На рис.3 представлень измеренные показатели выходной мощности и оптического спектра. На рис. 4 дано сравнение произведенных тремя компаниями.

Из рис. 3 можно увидеть, что изменение Из рис. выходнй мощности диодног лазера с нескольBWT меньше по сра внению с этим же потазатеBWT меньше по сравненй с этим же показателем, но для лазеров, произведенных двумя другими компаниями. Выходная мощностьлазеров всех трех компаний снижается по мере повышения температуры, при этом показатели лазера компании № 01 имеют самый низкий уровень. Лазер компании № 02 сопоставим с лазером компании BWT (он незначительно хуже, чем лазер компании BWT). Сравнение трех лазеров показывает, что оптические компоненты и про-

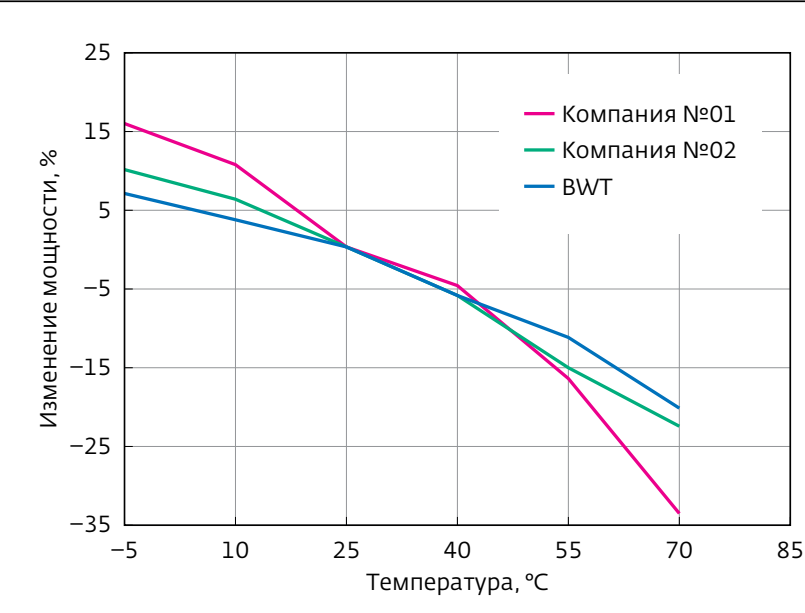

Pис.4. Коэффициент изменения мощности в зависимости от рабочей температуры, полученный с испопьзованием лазеров трех компаний с одинаковой мощностью и конструкцией

Таблица 2(a). Условия проведения ускоренного испытания на долговечность лазерных модулей с одиночным излучателем и волоконными выводами, в которых используется крепление КНП индием

\begin{tabular}{|l|l|l|l|l|l|}
$\begin{array}{l}\text { Группа } \\
\text { испы- } \\
\text { таний }\end{array}$ & Описание & Количество образцов & $\begin{array}{l}\text { Время ускоренного испы- } \\
\text { тания долговечности (4) }\end{array}$ & $\begin{array}{l}\text { Условия испытания } \\
\text { долговечности }\end{array}$ & Результаты \\
\hline 1 & $830-1,0$ Вт & 18 & 2000 & $1,4 \mathrm{~A}, 40^{\circ} \mathrm{C}$ & Pис.5a \\
\hline 2 & $808-4,0 \mathrm{BT}$ & 12 & 2000 & $5,0 \mathrm{~A}, 40^{\circ} \mathrm{C}$ & Pис.5b \\
\hline
\end{tabular}

Таблица 2(b). Условия проведения ускоренного испытания на долговечность лазерных модулей с несколькими одиночными излучателями и волоконными выводами, в которых используется крепление KHП AuSn

\begin{tabular}{|c|c|c|c|c|c|c|c|}
\hline $\begin{array}{l}\text { Группа } \\
\text { испы- } \\
\text { таний }\end{array}$ & Поставщик № & $\begin{array}{l}\text { Описание } \\
\text { 9ххнм }\end{array}$ & $\begin{array}{l}\text { Кол-во } \\
\text { излучате- } \\
\text { лей в одном } \\
\text { модуле }\end{array}$ & $\begin{array}{l}\text { Количество } \\
\text { образцов }\end{array}$ & $\begin{array}{l}\text { Время ускорен- } \\
\text { ного испытания } \\
\text { долговечности (4) }\end{array}$ & $\begin{array}{l}\text { Условия испы- } \\
\text { тания долго- } \\
\text { вечности }\end{array}$ & Результаты \\
\hline 3 & А, пластина-01 & $20 \mathrm{BT}$ & 2 & 11 & 2000 & $11,4 \mathrm{~A}, 45^{\circ} \mathrm{C}$ & Puc.6a \\
\hline 4 & А, пластина-02 & $25 \mathrm{BT}$ & 3 & 11 & 1000 & $10,7 \mathrm{~A}, 45^{\circ} \mathrm{C}$ & Puc.6b \\
\hline 5 & А, пластина-03 & $30 \mathrm{BT}$ & 3 & 12 & 2000 & $12,0 \mathrm{~A}, 35^{\circ} \mathrm{C}$ & Puc.6c \\
\hline 6 & B & $25 \mathrm{BT}$ & 3 & 9 & 6000 & $10,0 \mathrm{~A}, 35^{\circ} \mathrm{C}$ & Puc.6d \\
\hline 7 & c & $45 \mathrm{BT} \sim 60 \mathrm{BT}$ & $6 \sim 7$ & 11 & 2000 & Iop, $45^{\circ} \mathrm{C}$ & Puc.7a \\
\hline
\end{tabular}

Таблица 2(c). Условия проведения ускоренного испытания на долговечность лазерных модулей с одиночным излучателем и волоконными выводами, в которых используется крепление КHП AuSn

\begin{tabular}{|c|c|c|c|c|c|c|}
\hline $\begin{array}{l}\text { Группа } \\
\text { испы- } \\
\text { таний }\end{array}$ & Поставщик № & Описание & $\begin{array}{l}\text { Количество } \\
\text { образцов }\end{array}$ & $\begin{array}{l}\text { Время ускоренного } \\
\text { испытания долговеч- } \\
\text { ности (4) }\end{array}$ & $\begin{array}{l}\text { Условия испы- } \\
\text { тания долговеч- } \\
\text { ности }\end{array}$ & Результаты \\
\hline 8 & c & $915-10,0$ B T & 16 & 2000 & $11,3 \mathrm{~A}, 40^{\circ} \mathrm{C}$ & Puc.7b \\
\hline 9 & c & $\begin{array}{l}\text { 976-9,0 BT - } \\
\text { wavelock }\end{array}$ & 11 & 3000 & $12,0 \mathrm{~A}, 45^{\circ} \mathrm{C}$ & Рис. 8 \\
\hline
\end{tabular}




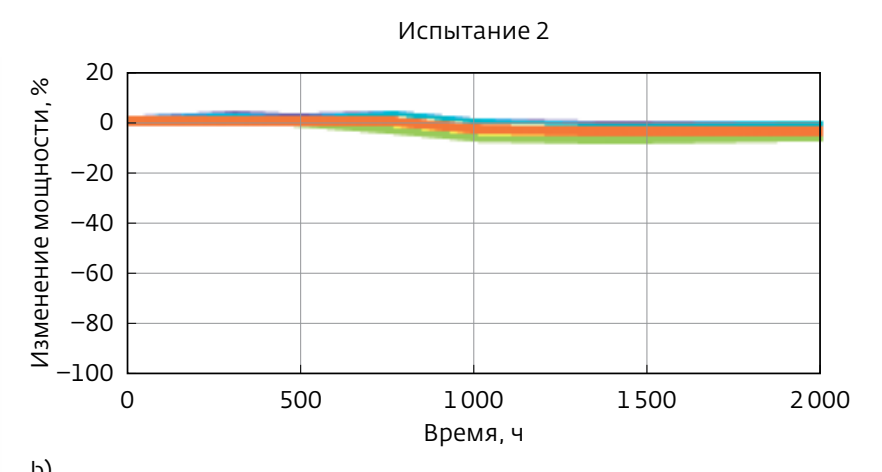

b)

Puc.5. Результаты ускоренного испытания на долговечность

цессы, используемые в лазерах компании BWT, имеют высокую стабильность и прогнозируемую высокую надежность работы.

Смещение длины волны лазера компании BWT из-за изменения температуры составляет $\delta \lambda / \delta \mathrm{T}=0,31 \mathrm{Hм} /{ }^{\circ} \mathrm{C}$. Для лазеров компании № 01 и 02 это значение составляет $0,34 \mathrm{Hm} /{ }^{\circ} \mathrm{C}$ и $0,37 \mathrm{Hm} /{ }^{\circ} \mathrm{C}$ соответственно. Смешение длин волны лазера компанин BWT меньше, чем у лазеров, произведенных другими двумя компаниями, Это также указывает на то, что в диодном лазере, изготовленным компанией BWT, достигается низкий показатель тепло-

вого сопротивления вследствие хорошего тер мального контроля, хорошего крепления, a также стабильного оптического дизайна и технологии.

4. РЕЗУЛЬТАТЫ ИСПЫТАНИЙ

ДОЛГОВРЕМЕННОЙ СТАБИЛЬНОСТИ

\section{1 .}

\section{на долговечность}

В зависимости от длины волны, типа корпуса иыходной мощности лазеров мы поделили лазерые модули с волоконными выводами на разные категории. В отличие от лазеров с одним одиноч-
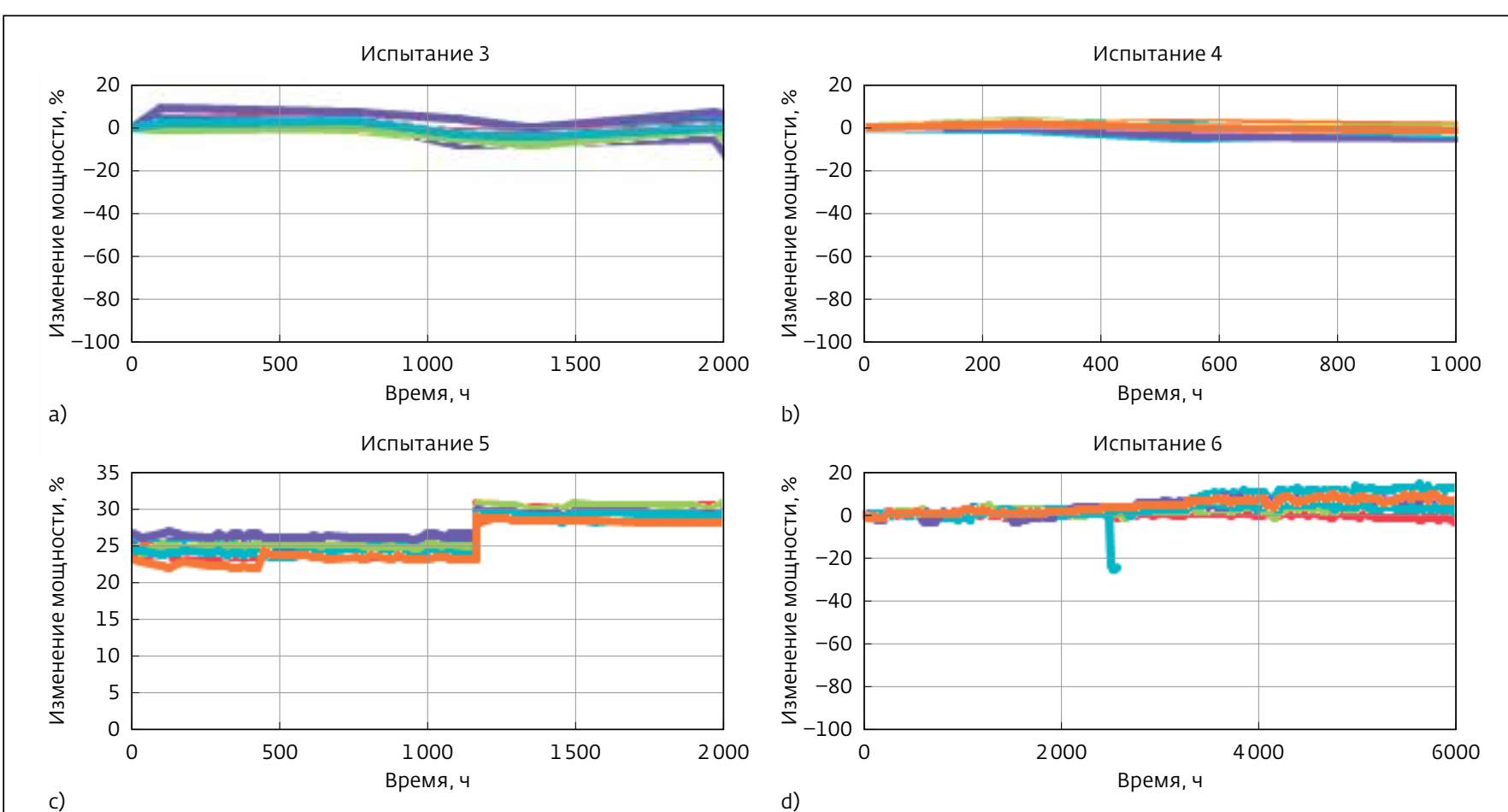

Puс.6. Результаты ускоренного испытания на допговечность
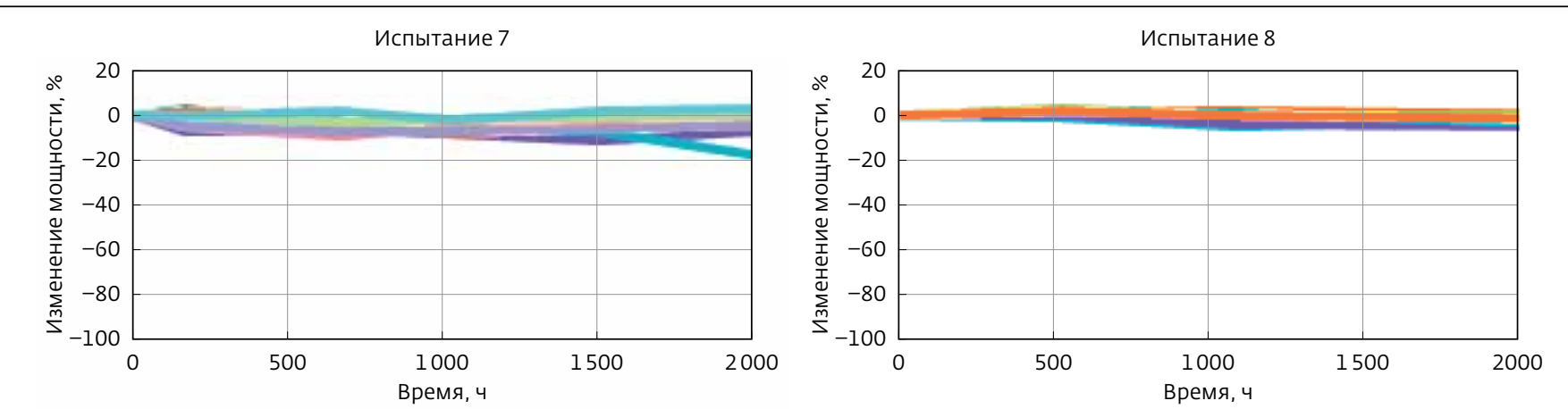

Puс.7. Результаты ускоренного испытания на долговечность (испытание 8 продолжается)

ным излучателем, лазерные модули с несколькими одиночными излучателями состоят из лазеров, у которых на один модуль приходится от 2 до 7 излучателей.

В соответствии с вышеописанной процедурой ускоренных испытаний на долговечность повышенная температура применяется в качестве рагрузии для ускорения испытания на определенагрузии для ускорения исп тения ва определей дол возбуждения эгих лазерных модулей остави ток возбуждения этих лазерных модупей оставляли постоян выходной мощности (Испьтание 1 - Испытание и длины волны в ходе проведения этих экспериментов. В табл. 2 даны условия проведения этих экпериментов.

Испытание 1 и Испытание 2 (рис.5) являются ускоренными испытаниями на долговечност лазерных модулей с одиночным излучателем с диодными лазерами двух разных производителей. В приборах используется крепление кристаллов индием с целью оценки срока службы азерных модулей $c$ волоконными выводами
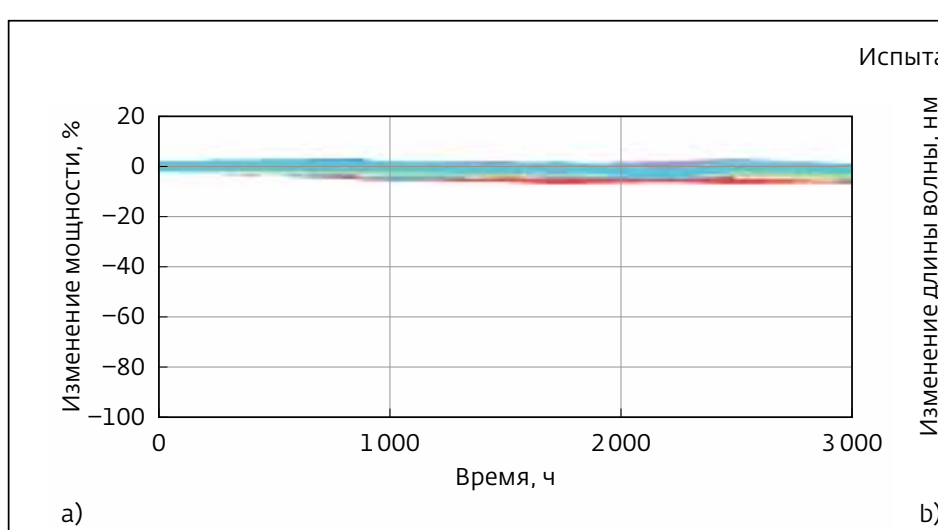

и индиевым креплением. В табл. 2 (а) подробно

Испытание 3 - Испытание 5 являются ускоренными испытаниями на долговечность лазерных модулей с с диодными лазерами, состоящими из нескольких одиночных излучателей, в которых используется крепление кристаллов с помощью AuSn на трех разных пластинах (рис.6). Приборы получены от олного и того же поставцика.

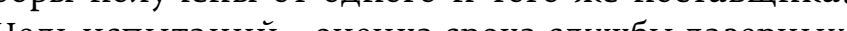

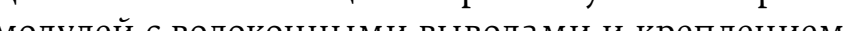

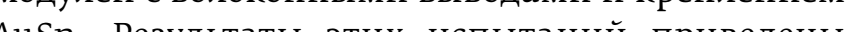
в табл. 2 (b). в отнов испи таний приведены испол 2 (b). В отношении испытания 5 были ислолезованы две стадии! первая стадия мспыта.5 25 Вт) на протяжении 1000 часов, а вторая стадия испытания проводилась при 12 А (порядка 30 Вт) на протяжении остальных часов.

Испытание 3 - Испытание 5, Испытание 6 и Испытание 7 (рис.7) являются ускоренными испытаниями на долговечность лазерных модулей с несколькими одиночными излучателями

Puс.8. Резупьтаты ускоренного испытания на долговечность: $a$ - мощннсть, b - средняя длина волны 
Таблица 3. Средняя наработка до отказа лазерных модулей

\begin{tabular}{|c|c|c|c|c|c|c|}
\hline $\begin{array}{l}\text { Группа } \\
\text { испыта- } \\
\text { ний }\end{array}$ & Описание & $\begin{array}{l}\text { Средняя наработка до } \\
\text { отказа при СL60\% (4.) }\end{array}$ & $\begin{array}{l}\text { Тип крепле- } \\
\text { ния }\end{array}$ & $\begin{array}{c}\text { Общая нара- } \\
\text { ботка до отказа } \\
\text { при СL60\% (4.) }\end{array}$ & $\underset{(4 .)}{\text { B05 при CL60\% }}$ & $\begin{array}{l}\text { B10 при } \\
\text { CL60\% (4.) }\end{array}$ \\
\hline 1 & 830-1,0 BT & 90965 & \multirow{2}{*}{ Индий } & \multirow{2}{*}{151608} & \multirow{2}{*}{7777} & \multirow{2}{*}{15979} \\
\hline 2 & $808-4,0$ BT & 60643 & & & & \\
\hline 3 & $9 x x-20 B T$ & 72258 & \multirow{5}{*}{ Ausn } & \multirow{5}{*}{177710} & \multirow{5}{*}{9116} & \multirow{5}{*}{18730} \\
\hline 4 & $9 x x-25$ BT & 36129 & & & & \\
\hline 5 & $9 \mathrm{xx}-30 \mathrm{BT}$ & 34219 & & & & \\
\hline 6 & $9 x x-25$ B & 80360 & & & & \\
\hline 7 & $9 \mathrm{xx}-45$ Вт $\sim 60$ ВТ & 72258 & & & & \\
\hline 8 & $915-10,0$ B T & $80857^{\circ}$ & Ausn & $80857^{*}$ & 4147 & 8522 \\
\hline 9 & $976-9,0$ B T & 108386 & $\begin{array}{c}\text { Стабилизи- } \\
\text { рованная } \\
\text { длина волны }\end{array}$ & 108386 & 5560 & 11424 \\
\hline
\end{tabular}

это ускоренное испытание на долговечность, Испытание 8, все еще продолжается. Общее количество часов является неполным по состоянию на данный момент

с диодными лазерами, в которых используется крепление кристаллов с помощью AuSn, полученных от трех различных поставщиков, с целью оценки срока службы лазерных модулей с волоконными выводами и креплением AuSn. Детальные данные этих испытаний можно увидет в таблице 2 (b). Модули, используемые в Испытании 7 , довольно отличаются от модулей, изготов ленных для Испытания 3 - Испытания 6. Модули для Испытания 7 были изготовлены из 6 или 7 одиночных излучателей в одном лазерном модуле. Его можно использовать для оценки степени надежности лазерных модулей с несколькими одиночными излучателями сверхвысокой яркости.

Испытание 8 (рис.7) представляет собой ускоренное испытание на долговечность лазерных модулей с одиночным излучателем с диодными лазерами, в которых используется крепление кристаллов с помощью AuSn, полученных от других поставщиков, с целью оценки срока службы лазерных модулей с волоконными выводами и крепле нием AuSn.

Образцы, используемые в Испытании 9 (рис.8), представляют собой лазерные модули с волоконными выводами и стабилизированной длиной волны, разработанные с целью достижения полосы поглощения 976 нм в сфере применения волоконных лазеров. Этот эксперимент проводился с целью оценки стабильности спектра оптиеского элемента с контролируемой длиной волны, используемого в этом модуле, а также производственного процесса для изготовления этого вида лазера. Детальная информация об этих испытаниях дана в таблице 2 (c).

\section{2. Анализ испытаний на долговечност}

Из результатов девяти ускоренных испытаний на долговечность можно видеть, что у большинства образцов сохраняется стабильный показатель мощности при испытаниях. Однако временами проявляется случайный отказ работы, но это не отказ вследствие износа. При критерии отказа $\Delta \mathrm{P} \leq+20 \%$ только один образец излучателя показал сбой работы среди обрего изличества 111 шатук сбой работы среди общего количества 111 штук испытуемых модулей с волоконными выводами (всего 242 излучателя). Среди них использовалис лазерные модули с несколькими одиночными злучателями высокой степени яркости в количестве 54 шт. Таким образом, вероятность безотказ ной работы готовых изделий после проведения ускоренного испытания на долговечность выше $8 \%$. Согласно модели Аррениуса может быть рас считана средняя наработка до отказа при температуре $25^{\circ} \mathrm{C}$; рассчитанные параметры показаны в табл. 3.

Результаты ускоренных испытаний на долговечность показывают, что и лазерные модули с одним одиночным излучателем, и лазер ные модули с несколькими одиночными излучателями обладают высокой надежностью. При использовании метода максимального правдоподобия [5] средняя наработка на отказ составила около 177 тыс. ч. (20 лет) при темпера тype $25^{\circ} \mathrm{C}$.

Наши клиенты из промышленных и медицинских сфер применения лазеров требуют, чтобь средняя наработка на отказ при $25^{\circ} \mathrm{C}$ составляла более 100 тыс. ч. Таким образом, все ускоренные испытания на долговечность были проведен только для того, чтобы выполнить или даже пр взойти требования наших покупателей. В опр деленный момент, когда эти результаты были достигнуты, проведение экспериментов было остановлено. Хотя продолжение эксперименто помогло бы установить, что продолжительность средней наработки на отказ может быть намного выше.

Когда клиенты используют оборудование в раз й рабочих условиях, фактический срок службы может отличав

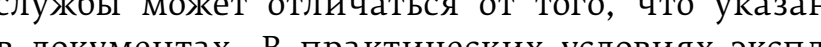
в документах. в практичеси у условиях эксплуВ даций все лазернве модули с несколькими одиоочными излучателями компании BWT, которье мы доставили покупателям несколько лет наза (в целом около 100000 единиц лазерных модулей с несколькими одиночными излучателям компании BWT), в настоящее время все еще находятся в эксплуатации с общей наработкой около 1000000000 часов на устройство. Можно сделат вывод о том, что наша конструкция, техника и технология эффективны для повышения рабочих характеристик, качества и надежности этого вида диодных лазеров с несколькими одиночными излучателями.

\section{5. ВЫВОДЫ}

В настоящей работе использованы различные кристаллы, полученные от разных поставщиков, монтаж которых осуществлялся на подложках разного типа. Были оптимизированы технология и условия крепления. На основании усовершенствованного процесса крепления все ины КНП установлены в модули с несколькими одиночными излучателями для того, чтоб

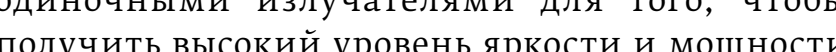
получить высокий уровень яркости и мощности
с оптоволоконного выхода. Изменение мощно сти и смещение длины волны излучения были зарегистрированы при воздействии различных рабочих температур. Изменение мощности и длины волны в лазерных модулях также было зарегистрировано в ходе проведения ускоренных испытаний на долговечность. Результаты испытаний показывают, что компания BWT обладает способностью создавать диодные сборки и модули из раздичных кристалтов, вырашенных разными производителями. Результаты подтвердили, что процесы крепления кристаллов и их установии, выработаннне в компании BWT, способствуют созданию модулей с оптическим излучением высохой яркости, при этом сушест из тозием высокой яркости, при этом сущиетвет возможность контроля стабильности продолжительность наработки на отказ в отно.777 177 тыс. ч (порядка 20 лет). В реальных условиях эксплуатации, а также согласно данным обратной связи с покупателями, можно отметить, что наши модули с несколькими одиночными излучателями вновь показали высокий уровень надежности и эффективности, который превышает ожидания клиентов. Исследования, описанные в настоящей работе, могут служить руководспвом по получению диодных лазеров с более высокой эффективностью и надежностью работы в отношении соответствующих сфер примене-
ния в будушем.

ЛИТЕРАТУРА

1. S.Patterson. Advances in High Power, High Efficiency, High Brightness Fiber Coupled Diode Lasers from 635-nm to 1900-nm and Beyond. 20th Annual Solid State and Diode Laser Technology Review, 2007

2. Telcordia Technologies, Generic Reliability Assurance Requirements for Optoelectronic Devices Used in Telecommunications Equipment. - An SAIC Company, 2004.

3. V.Rossin, E. Zucker, M. Peters, M. Everett, B.Acklin. High-Power High-Efficiency 910-980nm Broad Area Laser Diodes. - Proc. of SPIE, 2004, v.5336, 5336-27.

4. http://www.ansys.com

5. L.Bao, P. Leisher, J.Wang, M.Devito, D.Xu M. Grimshaw. High Reliability and High Performance of 9xx nm Single Emitter Laser Diodes. - SPIE LASE. International Society for
Optics and Photonics, 2011, v.791806, 791806-12.

Компания ОЭС "Спецпоставка" представляет весь спектр продукции BWT Beijing Ltd на территории РФ и предяагает наиболее выгодные условия поставки продукции, полную техническую поддержкку, а также поставку образцов. 